Ryan Susantio, Diah Ayu Candraningrum: Pengaruh Brand Image Oi-Dakk dengan penggunaan Endorser untuk promosi di Instagram terhadap Minat Beli Konsumen

\title{
Pengaruh Brand Image Oi-Dakk dengan penggunaan Endorser untuk promosi di Instagram terhadap Minat Beli Konsumen
}

\author{
Ryan Susantio, Diah Ayu Candraningrum \\ ryan.susantio@yahoo.com,diahc@fikom.untar.ac.id \\ Fakultas Ilmu Komunikasi Universitas Tarumanagara
}

\begin{abstract}
This study aims to find out how the role of Endorser creates Brand Image using Instagram in increasing consumer buying interest. The theory used in this study in communication, new media, brand image, endorser, and buying interest. The research method used is quantitative with the type of survey method. In this study using 97 respondents. The technique of collecting data using questionnaires and literature studies. Requirements test for data analysis using correlation coefficients, coefficient of determination, multiple correlation analysis, $T$ test, and $F$ test. The results of the correlation coefficient test are 0,871, meaning having a relationship between variables is very high, while the coefficient of determination is 75,9\% buying interest. Consumers are influenced by brand image and endorsers. The results of the T-test of the two variables are known that Ha is accepted, meaning that promotional communication carried out by creating a brand image and using endorsers influences the interest in buying Oi-Dakk products. Based on the results of the F-test, it is known that F count 147.970, Ha is accepted, meaning the brand image variable and endorser jointly influence consumer buying interest.
\end{abstract}

Keyword: Brand Image, Endorser, Instagram, Buy Interest

\begin{abstract}
Abstrak
Penelitian ini bertujuan untuk mengetahui bagaimana peran Endorser menciptakan Brand Image menggunakan instagram dalam meningkatkan Minat Beli konsumen. Teori yang digunakan dalam penelitian ini adalah komunikasi, new media, brand image, endorser, dan minat beli. Metode penelitian yang digunakan adalah kuantitatif dengan jenis metode survey. Pada penelitian ini menggunakan 97 responden. Teknik pengumpulan data menggunakan kuesioner dan studi kepustakaan. Uji persyaratan analisis data menggunakan koefisien korelasi, koefisien determinasi, analisis korelasi berganda, uji T, dan uji F. Hasil dari uji koefisien korelasi sebesar 0,871 artinya memiliki hubungan antar variabel sangat tinggi, sedangkan pada koefisien determinasi didapatkan hasil sebesar 75,9\% minat beli konsumen dipengaruhi oleh brand image dan endorser. Hasil uji T kedua variabel diketahui bahwa $\mathrm{Ha}$ diterima, artinya komunikasi promosi yang dilakukan menciptakan brand image dan menggunakan endorser berpengaruh terhadap minat beli produk Oi-Dakk. Berdasarkan hasil uji $\mathrm{F}$ diketahui $\mathrm{F}$ hitung 147,970 maka Ha diterima, artomya variabel brand image dan endorser secara bersama-sama berpengaruh terhadap minat beli konsumen.
\end{abstract}

Kata Kunci: Brand Image, Endorser, Instagram, Minat Beli 


\section{Pendahuluan}

Kehadiran teknologi internet membawa dampak pada kemajuan komunikasi manusia. Teknologi internet telah mengubah cara berkomunikasi yang lebih modern. Dengan kehadiran smartphone memudahkan manusia untuk berinteraksi satu dengan yang lain tanpa dibatasi oleh waktu, ruang, serta geografis.

Media baru adalah konsep yang menjelaskan kemampuan media dengan dukungan perangkat digital yang dapat mengakses kapan saja, dimana saja sehingga memberikan kesempatan bagi siapa saja, baik sebagai penerima atau pengguna untuk berpartisipasi aktif, interaktif, dan kreatif terhadap umpan balik pesan yang dapat membentuk komunitas atau masyarakat baru melalui media (Liliweri, 2015).

Fenomena yang muncul dari adanya Instagram menciptakan keunikan tersendiri dimana mulai muncul adanya endorser dengan berbagai macam konten menarik yang dijadikan sumber informasi serta hiburan pada followers atau pengikutnya. Endorser merupakan salah satu bentuk dari influencer marketing yaitu sebuah aktivitas pemasaran yang dilakukan menggunakan sebuah akun atau seseorang di media sosial dengan jumlah followers dan pengaruh yang signifikan.

Endoser juga diartikan sebagai orang yang dipilih mewakili image sebuah produk (product image). Biasanya dari kalangan tokoh masyarakat yang memiliki karakter menonjol dan daya tarik yang kuat (Hardiman, 2006).

Nugroho (2003) dalam Fiani \& Japarianto (2012) menyatakan bahwa image atau citra adalah realitas, oleh karena itu jika komunikasi pasar tidak cocok dengan realitas, secara normal realitas akan menang. Citra akhirnya akan menjadi baik, ketika konsumen mempunyai pengalaman yang cukup dengan realitas baru. Realitas baru yang dimaksud yaitu bahwa sebenarnya organisasi bekerja lebih efektif dan mempunyai kinerja baik.

Menurut Schiffman dan Kanuk (2012) dalam Oktaviana dan Subagio (2015) endorser dapat berperan dua macam dalam iklan. Endorser sebagai aktor yang menyajikan sebuah produk atau layanan jasa sebagai bagian dari karakter, dan juga mempresentasikan sebuah merek atau perusahaan dalam suatu jangka waktu tertentu Menurut Samat, et.al (2014) dalam Oktaviana dan Subagio (2015) kredibilitas endorser terdiri dari tiga dimensi yaitu :

1. Daya Tarik (Attractiveness)

Daya tarik dengan penampilan fisik atau kepribadian yang dirasakan oleh sumber, sehingga dapat menarik perhatian konsumen terhadap suatu produk. Oleh karena itu, pengiklan selalu memilih selebriti yang menarik secara fisik. Setiap daya tarik endorser dalam iklan dapat mempengaruhi sikap dan iklan.

2. Keahlian (Expertise)

Keahlian yang dimaksud adalah kemampuan endorser iklan untuk membujuk konsumen agar membeli produk. Efektifitas endorser dipengaruhi oleh persepsi konsumen terhadap keahlian endorser. Celebrity Endorser dianggap memiliki keahlian dibandingkan dengan orang dari masyarakat umum. Oleh karena itu, pengiklan harus dapat memprediksi keahlian endorser.

3. Kepercayaan (Trustworthiness)

Kepercayaan terhadap sumber merupakan hal yang penting dalam memberikan informasi-informasi. Para peneliti menentukan bahwa kepercayaan endorser iklan merupakan salah satu faktor penting untuk 
Ryan Susantio, Diah Ayu Candraningrum: Pengaruh Brand Image Oi-Dakk dengan penggunaan Endorser untuk promosi di Instagram terhadap Minat Beli Konsumen

mendapatkan niat beli konsumen, semakin tinggi kepercayaan maka semakin positif sikap terhadap merek. Endorser yang dipercaya dalam menyampaikan pesan menghasilkan perubahan sikap yang efektif.

Menurut Kotler \& Keller (2009) citra merek adalah persepsi dan keyakinan yang dipegang oleh konsumen, seperti yang dicerminkan asosiasi yang tertanam dalam ingatan konsumen.

Menurut Aaker \& Bisel (2009) Indikator-indikator yang membentuk brand image sebagai berikut :

1. Corporate Image (citra pembuat), yaitu sekumpulan asosiasi yang dipersepsikan konsumen terhadap perusahaan yang membuat suatu produk atau jasa. Meliputi : popularitas, kredibilitas, jaringan perusahaan, serta pemakai itu sendiri.

2. Product Image (citra produk) yaitu sekumpulan asosiasi yang dipersepsikan konsumen terhadap suatu produk atau jasa. Meliputi : atribut produk, manfaat bagi konsumen, serta jaminan.

3. User Image (citra pemakai) yaitu sekumpulan asosiasi yang dipersepsikan konsumen terhadap pemakai yang menggunakan suatu produk atau jasa. Meliputi : pemakai itu sendiri, serta status sosialnya.

Menurut Musay (2013) kesimpulan brand image merupakan gambaran atau kesan yang ditimbulkan oleh suatu merek dalam benak pelanggan. Penempatan citra merek dibenak konsumen harus dilakukan secara terus-menerus agar citra merek yang tercipta tetap kuat dan dapat diterima secara positif. Ketika sebuah merek memiliki citra yang kuat dan positif di benak konsumen maka merek tersebut akan selalu diingat dan kemungkinan konsumen untuk membeli merek yang bersangkutan sangat besar.

Menurut Mujiono (2009) dalam Helmi (2016) Minat beli merupakan aktivitas psikis yang timbul karena adanya perasaan (afeksi) dan pikiran (kognitif) terhadap suatu barang atau jasa yang diinginkan.

Menurut Ferdinand (2009) dalam Helmi (2016) minat beli dapat diidentifikasi melalui beberapa indikator yaitu:

a) Minat transaksional, yaitu kecenderungan seseorang untuk membeli produk.

b) Minat refrensial, yaitu kecenderungan seseorang untuk merefrensikan produk kepada orang lain.

c) Minat prefrensial, yaitu yang menggambarkan perilaku seseorang yang memiliki prefrensi utama pada produk tersebut. Preferensi ini hanya dapat diganti jika terjadi sesuatu kepada orang lain.

d) Minat eksploratif, minat ini menggambarkan perilaku seseorang yang selalu mencari informasi mengenai produk yang diminatinya dan mencari informasi produk mendukung sifat-sifat positif dari produk tersebut.

Penelitian ini bertujuan untuk mengetahui ada atau tidaknya pengaruh brand image melalui kegiatan promosi di instagram terhadap minat beli konsumen, untuk mengetahui ada atau tidaknya pengaruh endorser melalui instagram terhadap minat beli konsumen. 


\section{Metode Penelitian}

Dalam penelitian ini, peneliti memilih pendekatan penelitian kuantitatif dengan metode survey. Menurut Kriyantono (2010) survey adalah metode riset dengan menggunakan kuesioner sebagai instrument pengumpulan datanya. Tujuannya untuk memperoleh informasi tentang sejumlah responden yang dianggap mewakili populasi tertentu. Dalam survey proses pengumpulan dan analisis data sosial bersifat sangat terstruktur dan mendetail melalui kuesioner sebagai instrument utama untuk mendapatkan informasi dari sejumlah responden yang diasumsikan mewakili populasi secara spesifik.

Berdasarkan data dari instagram milik Oi-Dakk terdapat 3.830 followers. Dalam penelitian ini, peneliti menetapkan jumlah sampel sebanyak 97 responden, dengan criteria sampel yang telah ditentukan sesuai dengan penelitian peneliti.

Teknk penentuan sampel yang digunakan pada penelitian ini didasarkan pada metode non probability sampling dengan menggunakan pendekatan purposive sampling. Data dikumpulkan dengan penyebaran kuesioner dengan menggunakan skala likert. Data primer dalam penelitian ini melalui penyebaran kuesioner, sedangkan data sekunder melalui studi kepustakaan dan internet. Untuk mengetahui keabsahan data dalam penelitian ini, peneliti menggunakan uji validitas, uji reabilitas, dan uji normalitas. Sedangkan untuk pengolahan data dalam determinasi, analisis regresi linier berganda, uji $\mathrm{T}$, dan uji $\mathrm{F}$. Hipotesis dalam penelitian ini adalah:

Ha1: Terdapat pengaruh brand image terhadap minat beli Oi-Dakk.

$\mathrm{Ho}_{1}$ : Tidak terdapat pengaruh brand image terhadap minat beli Oi-Dakk.

$\mathrm{Ha}_{2}$ : Terdapat pengaruh endorser terhadap minat beli Oi-Dakk.

$\mathrm{Ho}_{2}$ : Tidak terdapat pengaruh endorser terhadap minat beli Oi-Dakk.

Ha3: Terdapat pengaruh brand image dan endorser terhadap minat beli Oi-Dakk.

Ho3: Tidak terdapat pengaruh brand image dan endorser terhadap minat beli OiDakk.

\section{Hasil Temuan dan Diskusi}

Berdasarkan nilai rata-rata untuk variabel $\mathrm{X}_{1}$ (brand image), dimensi tertinggi ada pada dimensi Corporate Image yang paling mempengaruhi minat beli konsumen. Untuk nilai rata-rata variabel $\mathrm{X}_{2}$ (endorser), dimensi tertinggi ada pada dimensi trust yang paling berpengaruh minat beli konsumen.

Peneliti menyebarkan kuesioner kepada 97 responden. Dari 97 responden, mayoritas responden adalah perempuan. Dari data 97 responden, peneliti melakukan keabsahan data melalui uji validitas, uji reabilitas, dan uji normalitas untuk menguji 27 pernyataan yang terdapat pada kuesioner.

\begin{tabular}{|c|c|c|c|c|}
\hline \multicolumn{5}{|c|}{ Item-Total Statistics } \\
\hline & Scale & Scale & & Cronbac \\
\hline $\mathrm{X}_{1}$ (brand image) & Mean if & Variance if & Corrected & h's Alpha \\
\hline $\mathrm{X}_{2}$ (endorser) & Item & Item & Item-Total & if Item \\
\hline Y (Minat Beli) & Deleted & Deleted & Correlation & Deleted \\
\hline $\mathrm{X}_{1}-\mathrm{P} 1$ & 18.29 & 12.999 & 0,675 & 0,863 \\
\hline$X_{1}-P 2$ & 18.10 & 13.760 & 0,754 & 0,852 \\
\hline$X_{1}-P 3$ & 18.46 & 12.668 & 0,730 & 0,853 \\
\hline
\end{tabular}


Ryan Susantio, Diah Ayu Candraningrum: Pengaruh Brand Image Oi-Dakk dengan penggunaan Endorser untuk promosi di Instagram terhadap Minat Beli Konsumen

\begin{tabular}{|c|c|c|c|c|}
\hline $\mathrm{X}_{1}-\mathrm{P} 4$ & 18.27 & 13.011 & 0,754 & 0,849 \\
\hline $\mathrm{X}_{1}-\mathrm{P} 5$ & 18.34 & 13.893 & 0,685 & 0,861 \\
\hline $\mathrm{X}_{1}-\mathrm{P} 6$ & 18.23 & 14.177 & 0,562 & 0,880 \\
\hline $\mathrm{X}_{2}-\mathrm{P} 7$ & 44.14 & 83.066 & 0,750 & 0,952 \\
\hline $\mathrm{X}_{2}-\mathrm{P} 8$ & 44.23 & 83.736 & 0,752 & 0,952 \\
\hline $\mathrm{X}_{2}-\mathrm{P} 9$ & 44.42 & 83.698 & 0,688 & 0,954 \\
\hline $\mathrm{X}_{2}-\mathrm{P} 10$ & 44.41 & 84.412 & 0,702 & 0,953 \\
\hline $\mathrm{X}_{2}-\mathrm{P} 11$ & 44.48 & 82.989 & 0,781 & 0,951 \\
\hline $\mathrm{X}_{2}-\mathrm{P} 12$ & 44.35 & 82.168 & 0,802 & 0,951 \\
\hline $\mathrm{X}_{2}-\mathrm{P} 13$ & 44.45 & 82.503 & 0,765 & 0,952 \\
\hline $\mathrm{X}_{2}-\mathrm{P} 14$ & 44.45 & 82.860 & 0,804 & 0,951 \\
\hline $\mathrm{X}_{2}-\mathrm{P} 15$ & 44.50 & 82.695 & 0,808 & 0,951 \\
\hline $\mathrm{X}_{2}-\mathrm{P} 16$ & 44.47 & 82.273 & 0,851 & 0,949 \\
\hline $\mathrm{X}_{2}-\mathrm{P} 17$ & 44.42 & 83.551 & 0,724 & 0,953 \\
\hline $\mathrm{X}_{2}-\mathrm{P} 18$ & 44.46 & 83.430 & 0,800 & 0,951 \\
\hline $\mathrm{X}_{2}-\mathrm{P} 19$ & 44.36 & 82.634 & 0,781 & 0,951 \\
\hline $\mathrm{Y}-\mathrm{P} 20$ & 25.23 & 29.156 & 0,630 & 0,936 \\
\hline $\mathrm{Y}-\mathrm{P} 21$ & 24.93 & 28.651 & 0,775 & 0,926 \\
\hline $\mathrm{Y}-\mathrm{P} 22$ & 24.95 & 27.112 & 0,817 & 0,923 \\
\hline $\mathrm{Y}-\mathrm{P} 23$ & 25.04 & 27.727 & 0,775 & 0,926 \\
\hline $\mathrm{Y}-\mathrm{P} 24$ & 25.03 & 27.676 & 0,832 & 0,922 \\
\hline $\mathrm{Y}-\mathrm{P} 25$ & 25.07 & 27.255 & 0,852 & 0,920 \\
\hline $\mathrm{Y}-\mathrm{P} 26$ & 25.07 & 27.797 & 0,732 & 0,929 \\
\hline $\mathrm{Y}-\mathrm{P} 27$ & 25.23 & 28.344 & 0,772 & 0,926 \\
\hline
\end{tabular}

\section{Uji Realibilitas $\mathbf{X}_{1}$}

Setelah diuji menggunakan SPSS, peneliti mendapatkan kasil 0,881 untuk pernyataan variabel $\mathrm{X}_{1}$ (brand image). Pernyataan variabel tersebut dinyatakan reliabel, karena Cronbach's Alpha $>0,6$ yaitu 0,881 >0,6.

\section{Uji Realibilitas $\mathbf{X}_{2}$}

Setelah diuji menggunakan SPSS, peneliti mendapatkan kasil 0,955 untuk pernyataan variabel $\mathrm{X}_{2}$ (endorser). Pernyataan variabel tersebut dinyatakan reliabel, karena Cronbach's Alpha > 0,6 yaitu 0,955 >0,6.

\section{Uji Realibilitas Y}

Setelah diuji menggunakan SPSS, peneliti mendapatkan kasil 0,935 untuk pernyataan variabel Y (minat beli). Pernyataan variabel tersebut dinyatakan reliabel, karena Cronbach's Alpha >0,6 yaitu 0,935 >0,6.

\section{Uji Normalitas}

Setelah diuji menggunakan SPSS, hasil uji normalitas menunjukkan nilai signifikansi sebesar 0,200, karena hasil signifikansi lebih besar dari 0,05 maka data dalam penelitian ini dinyatakan terdistribusi normal.

Hasil analisis data:

\section{Koefisien Korelasi}


Model Summaryb

\begin{tabular}{r|r|r|r|r}
\hline \multicolumn{1}{c|}{ Model } & \multicolumn{1}{c|}{$\mathrm{R}$} & \multicolumn{1}{c|}{ R Square } & \multicolumn{1}{c}{$\begin{array}{c}\text { Adjusted R } \\
\text { Square }\end{array}$} & $\begin{array}{c}\text { Std. Error of } \\
\text { the Estimate }\end{array}$ \\
\hline 1 & $0,871 \mathrm{a}$ & 0,759 & .754 & 2.985 \\
\hline
\end{tabular}

a Predictors: (Constant), Endorser, Brand Image

b Dependent Variable: Minat Beli

Sumber: SPSS Ver. 23.0

Setelah diuji menggunakan SPSS, peneliti mendapatkan hasil bahwa koefisien korelasi $(\mathrm{R})$ dari variabel $\mathrm{X}_{1}, \mathrm{X}_{2}$ dan $\mathrm{Y}$ dalam penelitian ini sebesar 0,871. Apabila nilai $\mathrm{R}$ sebesar 0,871 menunjukkan hubungan antara $\mathrm{X}_{1}$ (brand image), $\mathrm{X}_{2}$ (endorser) dan minat beli $(\mathrm{Y})$ adalah sangat tinggi. Pernyataan ini didasari oleh Nisfiannoor (2013).

\section{Koefisien Determinasi}

Setelah diuji menggunakan SPSS, peneliti mendapatkan hasil nilai koefisien determinasi dengan melihat angkat yang ada pada R Square. Hasil dari R Square adalah 0,759 sama dengan $75,9 \%$ yang artinya kemampuan brand image dan endorser dalam mempengaruhi minat beli konsumen cukup tinggi karena nilai koefisien determinasi mendekati angkat satu dan dikatakan bahwa sebesar 75,9\% minat beli konsumen dipengaruhi oleh brand image dan endorser, sedangkan sisanya $24,1 \%$ menunjukkan minat beli konsumen dipengaruhi oleh faktor-faktor lain.

\section{Analisis Regresi Linier Berganda}

Gambar 2. Analisis Regresi Linier Berganda dan Uji T

\section{Coefficientsa}

\begin{tabular}{|c|c|c|c|c|c|c|}
\hline \multirow[b]{2}{*}{ Model } & & \multicolumn{2}{|c|}{$\begin{array}{l}\text { Unstandardized } \\
\text { Coefficients }\end{array}$} & \multirow{2}{*}{$\begin{array}{c}\begin{array}{c}\text { Standardized } \\
\text { Coefficients }\end{array} \\
\text { Beta }\end{array}$} & \multirow[b]{2}{*}{$\mathrm{t}$} & \multirow[b]{2}{*}{ Sig. } \\
\hline & & B & Std. Error & & & \\
\hline & (Constant) & .463 & 1.672 & & .277 & .783 \\
\hline & Brand Image & .576 & .099 & .416 & 5.848 & .000 \\
\hline & Endorser & .323 & .044 & .527 & 7.402 & .000 \\
\hline
\end{tabular}

a Dependent Variable: Minat Beli

Sumber: SPSS Ver. 23.0

$$
\mathbf{Y}=\mathbf{a}+\mathbf{B}_{1} \mathbf{X}_{1}+\mathbf{B}_{2} \mathbf{X}_{2}
$$

Setelah diuji menggunakan SPSS, peneliti mendapatkan hasil nilai sebesar 0,463 menyatakan konstanta dari fungsi regresi yang menunjukkan bahwa tidak ada kenaikan variabel $\mathrm{X}_{1}$ (brand image) dan $\mathrm{X}_{2}$ (endorser), maka variabel $\mathrm{Y}$ (minat beli) akan mencapai 0,463 . Setiap ada penambahan 1 angka atau perubahan variabel $\mathrm{X}_{1}$ 
Ryan Susantio, Diah Ayu Candraningrum: Pengaruh Brand Image Oi-Dakk dengan penggunaan Endorser untuk promosi di Instagram terhadap Minat Beli Konsumen

(brand image), maka variabel Y (minat beli) akan mengalami peningkatan sebesar 0,576 dan setiap ada penambahan angka atau perubahan $\mathrm{X}_{2}$ (endorser), maka variabel Y (minat beli) akan mengalami peningkatan sebesar 0,323. Hal ini menunjukkan semakin besar nilai variabel $\mathrm{X}$ maka akan semakin mempengaruhi kenaikan nilai Y.

\section{Uji T}

Setelah diuji menggunakan SPSS, peneliti mendapatkan hasil uji $\mathrm{T}$ variabel $\mathrm{X}_{1}$ adalah 5,848 serta nilai sig $<a$ yaitu $0,000<0,05$, maka Ha diterima, artinya terdapat pengaruh brand image terhadap minat beli konsumen. dan variabel $\mathrm{X}_{2}$ adalah 7,402 serta nilai sig < $a$ yaitu $0,000<0,05$, maka Ha diterima, artinya terdapat pengaruh endorser terhadap minat beli konsumen.

\section{Uji F}

Gambar 3. Hasil Uji F

ANOVAa

\begin{tabular}{rl|r|r|r|l|l}
\hline \multicolumn{1}{l|}{ Model } & & Sum of Squares & df & Mean Square & F & Sig. \\
\hline 1 Regression & 2636.612 & 1 & 1318.306 & 147.970 & $.000 \mathrm{~b}$ \\
& Residual & 837.470 & 95 & 8.909 & & \\
Total & 3474.082 & 96 & & & \\
\hline
\end{tabular}

a Dependent Variable: Minat Beli

b Predictors: (Constant), Endorser, Brand Image

\section{Sumber: SPSS Ver. 23.0}

Setelah diuji menggunakan SPSS, peneliti mendapatkan nilai $F_{\text {hitung }}$ adalah 147,970 serta nilai sig $<0,05$ yaitu $0,000<0,05$. Hal ini dapat dikatakan hasil uji $\mathrm{F}$ adalah Ho ditolak dan Ha diterima, artinya variabel $\mathrm{X}_{1}$ dan variabel $\mathrm{X}_{2}$ secara bersama-sama mempengaruhi variabel $\mathrm{Y}$, maka terdapat pengaruh brand image dan endorser terhadap minat beli konsumen.

\section{Kesimpulan}

Dalam variabel brand image $\left(\mathrm{X}_{1}\right)$ terdapat 3 dimensi, yaitu corporate image, product image, user image (Aaker \& Bisel, 2009:71). Ketiga dimensi tersebut dapat mempengaruhi minat beli konsumen. Karena suatu kegiatan promosi terkait brand image yang dilakukan Oi-Dakk telah diterima dengan baik terhadap konsumen yang mengetahui kegiatan promosi tersebut.

Dimensi corporate image merupakan dimensi tertinggi dalam mempengaruhi minat beli konsumen, hal ini karena konsep yang telah dibuat Oi-Dakk telah dilakukan dengan baik. Dalam meningkatkan minat beli, konsep komunikasi promosi yang baik dan menarik merupakan hal yang penting dan perlu diperhatikan perusahaan. Sehingga dengan memperhatikan hal tersebut dapat membuat konsumen tertarik dan mengingat suatu produk.

Dalam variabel endorser $\left(\mathrm{X}_{2}\right)$ terdapat 3 dimensi, yaitu Attractiveness, Expertise, Trustworthiness (Samat, et.al (2014), dalam Oktaviana dan Subagio 2015:2). Dimensi trustworthiness merupakan dimensi tertinggi dalam mempengaruhi 
minat beli konsumen, artinya dalam meningkatkan minat beli konsumen, endorser yang dilakukan dapat membangun kepercayaan konsumen terhadap produk tersebut, sehingga membuat konsumen tertarik dan menginginkan suatu produk.

Kesimpulan hasil dari penelitian ini adalah hubungan antara variabel brand image $\left(\mathrm{X}_{1}\right)$ dan variabel endorser $\left(\mathrm{X}_{2}\right)$ terhadap minat beli $(\mathrm{Y})$ adalah sangat tinggi, karena nilai dari koefisien korelasi dalam penelitian ini sebesar 0,871. Hasil koefisien determinasi, dikatakan bahwa minat beli konsumen Oi-Dakk dipengaruhi sebesar $75,9 \%$ oleh brand image dan endorser, sementara sisanya 24,1\% dipengaruhi oleh variabel-variabel lain. Kegiatan Komunikasi melalui brand image dan endorser mempengaruhi minat beli konsumen Oi-Dakk baik secara parsial maupun bersamasama

\section{Ucapan Terima Kasih}

Penulis mengucapkan terima kasih kepada Ibu Diah Ayu Candraningrum, S.T., M.B.A., M.Si, sebagai Dosen Pembimbing yang telah meluangkan waktu untuk membimbing penulis serta kedua orang tua, responden dan sahabat penulis yang telah memberikan dukungan kepada penulis.

\section{Daftar Pustaka}

Aaker, David A, Alexander, L Biel. (2009). Brang quity and advertising: advertising role in building strong brand. Hillsdale: Lawrence Erlbaum Associates, Inc.

Fransisca Paramitasari, Musay(2013).Pengaruh Brand Image Terhadap Keputusan Pembelian (survey pada konsumen kfc kawi malang). Jurnal Administrasi Bisnis 3 http://administrasibisnis.studentjournal.ub.ac.id/index.php/jab/article/view/14 1

Fellyta, Oktaviana.S \& Hartono, Subagio. (2015). Analisa Pengaruh Kredibilitas Endorse dan Kreativitas Iklan Terhadap Sikap Terhadap Merek Melalui Efektifitas Iklan Sebagai Variabel Intervening. Jurnal Strategi Pemasaran Vol.3, No.1. http://publication.petra.ac.id/index.php/manajemenpemasaran/article/view/3395

Fransisca Paramitasari, Musay (2013).Pengaruh Brand Image Terhadap Keputusan Pembelian (survey pada konsumen kfc kawi malang). Jurnal Administrasi Bisnis 3 http://administrasibisnis.studentjournal.ub.ac.id/index.php/jab/article/view/14 1

Hardiman, Ima. (2006). Seri Pintar Public Relations: 400 Istilah PR Media \& Periklanan. Jakarta : Penerbit Gagas Ulung.

Kotler dan Keller. (2009). Manajemen Pemasaran. Jilid 1. (Edisi ke 13). Jakarta : Erlangga.

Kriyantono, Rachmat. (2010). Teknik Praktis Riset Komunikasi. Jakarta: Kencana Perdana

Liliweri, Alo. (2015). Komunikasi Antar Personal. Jakarta: Kencana

Margaretha, Fiani S dan Edwin, Japarianto (2012).Analisis Pengaruh Food Quality dan Brand Image Terhadap Keputusan Pembelian Roti Kecik Toko Roti Ganep's di Kota Solo. Jurnal Manajemen Pemasaran Vol.1, No.1, 1- 
Ryan Susantio, Diah Ayu Candraningrum: Pengaruh Brand Image Oi-Dakk dengan penggunaan Endorser untuk promosi di Instagram terhadap Minat Beli Konsumen

6http://publication.petra.ac.id/index.php/manajemenpemasaran/article/view/72

Nisfiannoor, Muhammad. (2013). Pendekatan Statistika Modern Aplikasi dengan Software SPSS dan E-Views. Jakarta: Penerbit Universitas Trisakti.

Mhd Sukri Helmi Nst (2016). Faktor-Faktor Yang Mempengaruhi Minat Beli Konsumen Pada CV.Master Pasir Pengaraian Kabupaten Rokan Hulu. Vol.3, No.1. http://e-journal.upp.ac.id/index.php/fekon/article/view/545/479 